\title{
Intellectual readiness of future engineers to master the disciplines of the professional curriculum part while online learning
}

\author{
Larisa Zanfirova, Tatyana Kovalenok*, Yana Chistova, and Natalya Sergeeva \\ Russian State Agrarian University - Moscow Timiryazev Agricultural Academy, 127550, Moscow, \\ Russia
}

\begin{abstract}
The concept of intellectual readiness for learning, which is considered as the main condition for successful education at a university, is defined. Developed competencies of BSc students in training area 35.03.06 "Agro engineering" were analyzed. This analysis demonstrates the importance of knowledge of the basic mathematical and natural laws for solving typical problems and participating in experimental professional research. The role of the "Electrical Materials"course in the development of students' general professional and specific professional competencies is revealed. The paper presents the research results identifying the relationship between the mental development level, formed in general education, and the success of mastering the "Electrical materials" course. At the same time, knowledge of scientific concepts, the development of the classification mental operation and the ability to perform mental actions by analogy turned out to be determining. According to the results of the research, five groups of students were identified. They differ in the success of the acquisition of knowledge and proximity to the socio-psychological standard. Quantitative and qualitative indicators of their mental development characteristics were also described. The specificity of the relationships between the parameters of intellectual readiness and success in mastering the discipline is described. It is concluded that it is necessary to stimulate the mental development of students in the process of developing professional competencies, taking into account the specific features of the structure of intellectual abilities, improving methods for assessing intellectual readiness.
\end{abstract}

\section{Introduction}

Readiness to study at a university is an integrative education that determines the success of students in educational activities, in which several components are distinguished: motivational readiness, intellectual readiness, organizational and communicative readiness [1]. Intellectual readiness is considered as the main condition for the success of training, since the possibility of the acquisition of knowledge at the highest level of education presupposes, in addition to the formation of general educational skills and abilities, the presence of a certain development level of mental abilities. Mental abilities are, on the one hand, the result of learning, and on the other, a prerequisite for learning. They characterize the achieved level

\footnotetext{
* Corresponding author: tkovalenok53@gmail.com
} 
of development of basic cognitive functions (perception, attention, memory, thinking, and imagination), the ability to identify essential connections, relationships between objects, patterns of their development and functioning, and the ability to apply abstract theoretical knowledge to solve specific practical problems.

The formation of intellectual readiness for studying at a university should be carried out in general education. The effectiveness of this process is ensured a number of conditions in the educational process. The main of them are activation of educational and cognitive activity, taking into account the individual characteristics of students, and purposeful formation of readiness to get specific empirical and theoretical knowledge. An analysis of readiness for training in engineering specialties is presented in the research papers of Matías Díaza et al [2].

Diagnostics of mental development can be one of the tools for assessing the intellectual readiness to study at a university. Our psychologists regard it as a result of mastering the content set by the educational programs of school disciplines [3]. A meta-analysis of learners' cognitive abilities across multiple indicators is presented in the article by Nils Machts, Johanna Kaise, Fabian T.C. Schmidt, Jens Moller, in which it is noted that mental development includes such components as intelligence, giftedness, creativity [4]. Mental development is manifested in the level of basic knowledge of academic disciplines, the ability to perform various actions with them and to use them for solving problems. For the diagnosis of mental development, tests are developed based on the principle of normative diagnostics, the measurement of the level of their effectiveness is assessed using the Learning Analytics (LA) System [5]. In contrast to the statistical norm, which is determined on the basis of the analysis of empirical indicators, the socio-psychological standard is set, it is $100 \%$ completion of all test tasks. This allows the students to be divided according to the level of success based on the objective criterion of proximity to the socio-psychological standard, to determine the features of mental development, to identify the current directions of its development, to predict success, including the success in the vocational education [6]. Test tasks designed to assess mental development include material from the school courses in physics, mathematics, literature, Russian, history, geography and biology, tasks for spatial thinking based on the material of geometry and drawing. The subtests "Analogy", "Classification", "Generalizations" reveal the ability to perform logical actions and operations with learned concepts, to move from abstract knowledge to its application in specific cases [7].

The training of specialists in vocational education institutions, implemented in accordance with the Federal State Educational Standard of Higher Education, implies the mastery of a number of competencies by a student. The competencies are divided into three groups: universal, general professional and specific professional competencies. The developed competencies provide for a harmoniously developed personality and a professional in a particular industry [8]. General professional (GPC) and specific professional (SPC) competencies develop professionally important abilities and qualities. The general professional competencies are spelt out in the Federal State Educational Standard of Higher Education and are uniform for the entire group of areas and specialties. Specific professional competencies are spelt out in the approximate basic educational program, and are the same for the same training areas. In addition to the professional competencies spelt out in the Federal State Educational Standard of Higher Education, there are also professional competencies ones that the educational institution develops independently, relying on the needs of the professional sphere, the market labor, social and economic indicators, etc. Six general professional competencies and three specific professional competencies are developed at Russian State Agrarian University - Moscow Timiryazev Agricultural Academy, while preparing BSc students in training area 35.03.06 "Agroengineering", program "Electrical Equipment and Electrical Technologies". One of the indicators of 
developing competencies is the ability to use knowledge: "The student uses the basic laws of natural science disciplines to solve standard problems in accordance with the direction of professional activity" (GPC-1.1.); "The student uses knowledge of the basic laws of mathematical and natural sciences to solve standard problems in agricultural engineering" (GPC-1.2.); "The student demonstrates knowledge of modern technologies in professional activities" (GPC-4.1), etc. It can be assumed that the general level of mental development, formed in general education, is the basis of readiness for developing professional competencies and should be taken into account when determining the methodology and techniques of teaching. Engineering education involves the preparation of students to solve technical and technological problems, which requires mastering a system of technical concepts, corresponding images and ideas $[9,10]$. This defines the structure of professional technical thinking as a unity of three components: conceptual, figurative and practical. It is obvious that the current level of development of the ability to operate with concepts and images is an important component of the readiness to master the disciplines of the professional curriculum part and, as a result, to develop the professional competencies of an engineer.

An objective assessment of the general readiness for learning, its motivational, organizational, communicative and intellectual components while online learning gets very actual, because the habitual set of tools that the teacher can use to organize and stimulate the educational activities of students is sharply limited and radically changed. At the same time, there are new opportunities for objective assessment, operational control, individualization of training [11].

At the Department of Automation and Robotization named after Academician Borodin I.F.of Russian State Agrarian University - Moscow Timiryazev Agricultural Academy teaching materials and monitoring tools for "Electrical materials" course are improved to increase the efficiency of professional training of engineers, taking into account the peculiarities of distance learning. In particular, the authors are developing a system of test tasks designed to develop general professional and specific professional competencies.

The "Electrical materials" course contributes to developing general professional competencies of students. In particular, during their first year, students must learn to solve typical problems of professional activity, based on natural science and mathematical laws, therefore, it is necessary to pay the greatest attention to the development of logical thinking. In addition, mastering the material, freshmen must develop the ability to implement modern technologies in professional activities, justify their use. The "Electrical materials" course is studied at the very beginning of training, and is the basis for further development of the educational program. Therefore, in addition to expanding professional knowledge, it lays the foundations of skills for more complex disciplines. Thus, this course develops elementary abilities in conducting further experimental research in professional activities.

Test tasks are developed by analogy with the tasks in the tests that determine the level of mental development (School Test of Mental Development (SHTUR), Test of an Applicant's and a Student's Mental Development (ASTUR), and their modifications). On the one hand it monitors the process of knowledge development; on the other hand, it contributes to the development of professional thinking, the ability to carry out logical actions and operations with the concepts of discipline, to solve problems that are elements of future professional activity $[12,13]$. There have been developed blocks of test tasks of various forms ("General awareness", "Analogies", "Excluding unnecessary", "Problems"), the content of which reflects the sections of the "Electrical materials" course and provides quick controlling the peculiarities of their mastering $[14,15]$.

Using this form of control made it possible to accumulate empirical material objectively assessing the effectiveness of the learning process, educational activities of students, identifying gaps in knowledge of certain sections [16]. Significant difficulties that students 
experienced in completing tasks related to understanding the meaning of the task, determining what is required, forced to conduct training sessions, which used the School Test of Mental Development (SHTUR) [https://psytests.org/iq/shtur/shturA-run.html]. The School Test of Mental Development consists of eight subtests: "Awareness" (two subtests), "Analogies", "Classifications", "Generalizations", "Number series", "Spatial representations" (two subtests). Tasks in the subtests are based on the material of school courses and are intended for students in grades 9-10. The subtests "General awareness" contain concepts of a scientific, cultural and socio-political nature, and the subtests "Analogy", "Classification", and "Generalizations" are built on the basis of concepts from the school courses in physics, mathematics, literature, Russian, history, geography and biology. Spatial thinking exercises include geometry and drafting material.

This knowledge is assumed to have already been sufficiently acquired and when performing the test, students will be able to focus on the analysis of logical relationships between the learned concepts. In addition to understanding the instructions for the test tasks, they will train in using the concepts, images and ideas learned at school [17, 18]. The data collected in diagnostics made it possible to implement the conducted research.

\section{Purpose of the research}

The aim of the research was to assess the intellectual readiness to master the "Electrical materials" course and to identify ways to increase the effectiveness of developing professional competencies.

\section{Research materials and methods}

The research included three stages. At the first stage, students performed a test based on the content of the first section of the "Electrical materials" course (at the end of the 1st semester). At the beginning of the second section of the course, as a training for the development of the ability to perform mental operations, students independently performed test SHTUR on the website psytests.org. At the end of the course, a test based on the materials of the 2nd section was carried out; test tasks were presented on the onlinetestpad.com platform, with a time limit for submitting tasks and observing other requirements for the objectivity of the data obtained.

The test results were presented in the form of the number of correct answers of the students for individual subtests and the percentage of correct answers as the number of tasks in the subtests differed. Online testing ensured strict adherence to instructions and controlled each subtesttime.

Sixty-three second year students aged 18 to $21,90 \%$ of boys, took part in testing.

Spearman's rank correlation coefficient was used to test the relationship between the indicators of mental development and the effectiveness of developing professional knowledge.

\section{Results}

Correlation analysis of the results of the SHTUR test and ongoing control tests in the "Electrical Engineering" course for all the students showed that most of the correlation coefficients are insignificant. Significant connections were found between the indicators of the "Problems" subtest in the second part of the educational test in the "Electrical Materials" course and the "General awareness" subtest (Spearman's correlation coefficient $0.456 \mathrm{p}$ $<0.05)$, between the "Analogies" subtest $(0.456 \mathrm{p}<0.05)$, the "Classification" subtest $(0.442$ 
$\mathrm{p}<0.05)$, and the overall result of the SHTUR test $(0.417 \mathrm{p}<0,05)$. These results can be explained by the fact that the course studying for two semesters led to mastering the basic concepts necessary for solving problems, and the success in completing the tests began to be determined by the general intellectual abilities, the level of development of mental operations. The lack of links with the results of academic tests for the first section of the course, by the authors' opinion, is explained by the fact that the content of the discipline was just being comprehended and knowledge was not sufficiently developed.

To determine the directions for increasing the online learning effectiveness and implementing an individual approach, the students were divided into subgroups according to the level of mental development and the degree of closeness to the socio-psychological standard (100\% of the SHTUR test). In total, five subgroups were identified, for each of the subgroups the average percentage of correctly completed tasks was calculated (Table 1).

Table 1.Criteria for the selection of subgroups of students according to the results of the SHTUR test.

\begin{tabular}{|c|l|c|c|c|}
\hline \multicolumn{1}{|c|}{ Subgroups } & $\begin{array}{c}\text { The } \\
\text { number of } \\
\text { students in } \\
\text { the } \\
\text { subgroup }\end{array}$ & $\begin{array}{c}\text { Intervals of } \\
\text { result values } \\
\text { according to } \\
\text { the SHTUR } \\
\text { test }\end{array}$ & $\begin{array}{c}\text { Percentage of completed } \\
\text { tasks }\end{array}$ \\
\hline 1 & Mostsuccessful & $10 \%$ & $131-128$ & 88 \\
\hline 2 & Closetosuccessful & $20 \%$ & $123-116$ & 81 \\
\hline 3 & $\begin{array}{l}\text { Average (in } \\
\text { terms of success) }\end{array}$ & $40 \%$ & $109-99$ & 70 \\
\hline 4 & Unsuccessful & $20 \%$ & $97-85$ & 59 \\
\hline 5 & Leastsuccessful & $10 \%$ & $76-61$ & 47 \\
\hline
\end{tabular}

The authors of the test guide provide an approximate scale for assessing individual test scores. High mental development of the 10th graders is determined if the overall test result is more than $80 \%$ of correctly completed tasks, low mental development is less than $36 \%$. Thus, it can be assumed that the average level is closer to the low mental development for most students. However, this can be interpreted as a manifestation of a specific structure of abilities, or a low level of residual knowledge of school subjects that do not correspond to the profile of vocational training.

To identify the features of the mental development of students with different levels of intellectual readiness, the success of performing different subtests of the SHTUR test was analyzed (Fig. 1).

The analysis of the structure of abilities showed that the results for the first two subtests, diagnosing mastering scientific and cultural concepts, are almost the same in four subgroups and differ significantly for the worse only in the subgroup of unsuccessful students. The most successful students coped best with the tasks for generalizing concepts and with verbal tests in general; the indicators of spatial thinking were somewhat worse. The students close to successful ones turned to fail to perform mental actions by analogy, while their results in all other subtests showed that they are quite close to the socio-psychological standard, and they surpassed the most successful students in terms of subtests for spatial representations. In the subgroup of average students (in terms of success), tasks requiring verbal-logical and spatial thinking were performed at approximately the same average level. Unsuccessful and least successful students are characterized by insufficient development of the recreational imagination, the poor ability to operate with images and a very low level of development of the ability to generalize. 


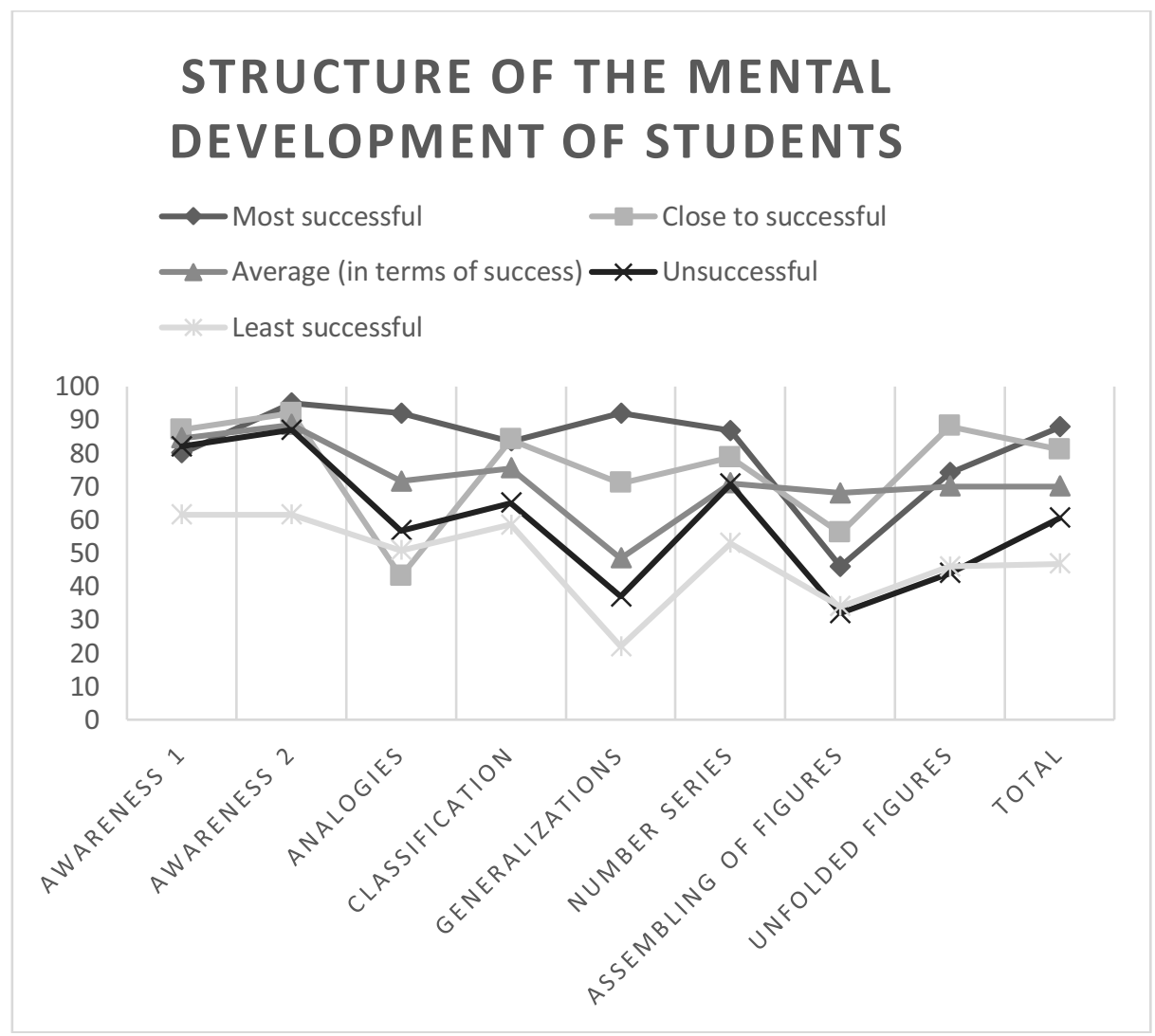

Fig. 1.The structure of the mental development of students with different levels of intellectual readiness.

To assess the influence of intellectual readiness on the acquisition of knowledge in the "Electrical Materials" course, the students were divided into three subgroups: "successful", "average", "unsuccessful". The first subgroup included the most successful students and those close to them, the second subgroup included the average (in terms of success) students, and the unsuccessful group was combined with the least successful one.

Correlation coefficients of data on the SHTUR tests and educational tests in subgroups were determined. The results of the correlation analysis showed that in the poorly successful subgroup there are no significant connections between the indicators of educational tests and the test of mental development. Perhaps a low level of general awareness and an insufficient level of intellectual readiness to study at a university are the reasons for difficulties in developing knowledge of the discipline, which makes the test results random.

In the average subgroup (in terms of success), a negative relationship was revealed between the results of the subtest "Generalizations" and the success of solving the problems of the second part of the educational test $(-0.814 \mathrm{p}<0.01)$. The performance of tasks for generalization presupposes the independent formulation of a general concept that reflects the essential features of the two presented concepts (for example: Science - Art). This requires considerable erudition, good speech development, verbal thinking. At the same time, only three out of 19 tasks are related to the main professional disciplines of engineering training mathematics, physics, and chemistry. According to the subtest "Spatial representations (assembling of figures)" and the overall result for the second part of the educational test, a positive relationship was revealed $(0.62 \mathrm{p}<0.05)$, which indicates the role of figurative thinking in the acquisition of knowledge of the discipline. Another positive relationship was 
determined between the total number of correct answers on the test SHTUR and the success of performing actions by analogy with the concepts of the "Electrical materials" course $(0.672$ $\mathrm{p}<0.05)$. Thinking actions by analogy symbolize the initial stage in the development of logical thinking, when a transition is made from the particular to the particular bypassing the general. Obviously, this is a feature of the thinking of this subgroup of students.

The most related results were those of diagnostics in the subgroup of successful students. There were seven significant correlations, but four of them turned out to be negative (see Table 2).

Table 2. Correlation analysis results in a sample of successful students.

\begin{tabular}{|l|c|c|}
\hline \multicolumn{1}{|c|}{ SHTUR } & $\begin{array}{c}\text { Spearman's correlation } \\
\text { coefficient }\end{array}$ & $\begin{array}{c}\text { "Electrical } \\
\text { materials" course }\end{array}$ \\
\hline Awareness 1 & $-0.709^{*}$ & Excluding excess 1 \\
\hline Awareness 2 & $0.883^{* *}$ & Awareness 1 \\
\hline Analogies representations & $-0.773^{*}$ & Excluding excess 2 \\
\hline Generalizations & $-0.856^{* *}$ & Problems 1 \\
\hline Number series Total 1 \\
\hline $\begin{array}{l}\text { Spatial } \\
\text { (assembling of figures) }\end{array}$ & $-0.892^{* *}$ & Total 1 \\
\hline $\begin{array}{l}\text { Spatial representations } \\
\text { (unfolded figures) }\end{array}$ & $0.674^{*}$ & \\
\hline
\end{tabular}

The negative relationship between the results of the first subtest on awareness and the positive relationship of the second subtest with the results on the educational test can be explained by the content of the tasks. The first subtest contains tasks related to concepts from the sphere of social science and politics, the second one - to the concepts of natural science disciplines. Negative relationships between the subtests that reveal the level of verbal thinking and positive ones between the subtests in visual-figurative thinking demonstrate the specificity of the requirements for the abilities of students for mastering the discipline of the professional curriculum part.

\section{Conclusion}

Empirical data showed the relationship between the level of students' knowledge of scientific concepts, the development of their mental operations and the ability to perform mental actions with the success of acquiring knowledge in the discipline of the professional curriculum part and the effectiveness of solving professional problems. The use of tests of mental development allows us to obtain a general assessment of the intellectual readiness of students to master the content of the professional disciplines, creates the basis for predicting professional success, and indicates the directions of individualization of training.

Identification of subgroups of students differing in the level of readiness to study at a university can become the basis for a differentiated approach to the selection of content and teaching methods. It seems appropriate to organize additional classes for the freshmen on the development and formation of general and professional intellectual abilities.

Another area of scientific and methodological work should be the improvement of methods for assessing intellectual readiness, it is important to harmonize the content of test tasks and requirements for technical thinking and the knowledge of an engineer. The test for assessing intellectual readiness should mainly consist of concepts related to the content of the main professional disciplines. 


\section{References}

1. N.N. Kolpakova, Formation of readiness of junior students for educational and professional activities at the university, dissertation ... candidate of pedagogical sciences 13.00.08 (Moscow, 2008).

2. M. Díaza, D. Gormaz-Lobosb, C. Galarce-Mirandab, F. Valenzuelaa, F. Rojasa, E. Sepulvedaa, A. Durána, C. Cerdaa, D. Carrascoa, H. Hortschb, STING Project. Procedia Computer Science 172, 597-602 (2020).

3. G.P. Loginova, Diagnostics of the mental development of adolescent children (MGPPU, Moscow, 2002).

4. Machts, N., Kaiser, J., Schmidt, F.T.C., Moller, J.: Accuracy of teachers' judgments of students' cognitive abilities: A meta-analysis. Educational Research Review 19, 85-103 (2020).

5. A. Joshi, P. Desai, P. Tewari, Procedia Computer Science 172, 954-959 (2020).

6. R. Gurumoorthy, N.S. Kumar, Procedia Computer Science 172, 709-717 (2020).

7. G. Alibakhshi, R. Javaheri, A. Labbafi, Heliyon 6, Article e05534 (2021).

8. D.J. Pons, Journal of Engineering and Technology Management 38, 89-101 (2015).

9. D. Lecorchick, J. Papadopoulos, L. Tabor, Procedia Computer Science 172, 838-842 (2020).

10. E. Lysenko, L. Nazarova, Development of Technical Thinking in Engineering Students, Advances in Social Science, Education and Humanities Research: 1st International Scientific Practical Conference "The Individual and Society in the Modern Geopolitical Environment” (ISMGE 2019) 331, 430-435 (2019).

11. Ting-Ting Wu, Yu-Tzu Wu, Thinking Skills and Creativity 35, Article 100631 (2020).

12. P. Kubrushko, S. Shishov, V. Kalnei, V. Scaramanga, N. Shafazhinskaya, R. Rabadanova, Comparative Analysis. International Journal of Civil Engineering and Technology (IJCIET) 9 (11), 2331-2337 (2018).

13. C. Wheatleya, N. Bealeb, T. Wassenaara, M. Grahamc, E. Eldridgeb, H. Dawesb, H. Johansen-Berg, Trends in Neuroscience and Education 20, Article 100134 (2020).

14. L.V. Zanfirova, T.P. Kovalenok, Y.S. Chistova, Modern Higher Education: Theory and Practice 353-362 (2020).

15. L.V. Zanfirova, T.P. Kovalenok, E.A. Ovsyannikova, Y.S. Chistova, N.A. Sergeeva, Journal of Physics: Conference Series 1691(1), Article 012222 (2020).

16. Zhuo Zhang, Yan Lei, Xiaoguang Mao, Meng Yan, Ling Xu, Xiaohong Zhang, Information and Software Technology 131, Article 106486 (2021).

17. R.S. Bednarz, J. Lee, Procedia Social and Behavioral Sciences 21, 103-107 (2011).

18. H. Hauptman, A. Cohen, Computers \& Education 57, 2106-2117 (2011). 